\title{
Somogy megye recésszárnyú-alkatúinak katalógusa (Megaloptera, Raphidioptera, Neuroptera)
}

\author{
ÁBRAHÁM LEVENTE
}

\begin{abstract}
ÁBRAHÁm L.: Checklist of the neuropteroid fauna of Somogy county (Megaloptera, Raphidioptera, Neuroptera) Abstract: Eighty-six neuropteroid species (3 Megaloptera, 6 Raphidioptera, 77 Neuroptera) are known to occur in Somogy county; which is 65 percentage of the number of neuropteroids recorded in Hungary. The first faunistical records were published in 1900. However, no important research on the neuropteroid fauna was done until the mid-1980s. Intensive fieldwork was carried out later, especially in the larger nature conservation areas. The first Hungarian records of Aleuropteryx juniperi and Myrmeleon bore are from Somogy county. Occurrence of three species (Acanthaclisis occitanica, Myrmecaelurus punctulatus and Hemerobius simulans), previously reported from the area, has not been confirmed during the fieldwork of the last fifteen years.
\end{abstract}

\section{Bevezetés}

Linnaeus 1758-ban recésszárnyúaknak (Neuroptera) nevezte a súrú hálózatos szárnyerezetü rovarokat. Így különböző fejlődésmenetú, egymástól taxonómiailag távoli rovarcsoportokat egyesített egy rendben (Ephemeroptera, Odonata, Plecoptera, Trichoptera, stb.). A tudomány fejlődésével azonban e rovarrendból sorra választották le az újabb és újabb rendeket, $s$ ma a Megaloptera, a Raphidioptera és a Neuroptera rendeket is önálló rendnek és nem a Planipennia (Neuroptera) rend alrendjeinek tekintjük. A Planipennia nevet az elmúlt évtizedben pedig a Neuroptera név használata váltotta fel, $s$ ebben az a tendencia fejezódik ki, hogy a rovarok rendjei -ptera végzódést kapjanak.

Hazánkban a Fauna Regni Hungariae (MoCSÁRY 1900) volt az első faunamú, melyben Somogyból Neuropteroidákra vonatkozó adatokat közöltek.

Ebben a munkában a Neuropterákat két alrendre osztják, Trichoptera és Planipennia. Ez utóbbi, család szintén magában foglalta a Megalopterákat (Sialidae) és a Mecopterákat is. A Raphidioptera rendet itt még a Sialidae család egy genuszaként említették meg. E faunakatalógus a történelmi Magyarország területéról 2 Megaloptera, 7 Raphidioptera és 57 Neuroptera fajt ismertet. Somogy megyéból azonban csupán két faj: a Myrmecaelurus punctulatus és a Creoleon plumbeus (=Creagris plumbeus), siófoki lelóhelyét közli. Ez rendkívül kevés adatnak túnik, de tudnunk kell, hogy akkoriban a terepi kutatások nagy része a Kárpátok, a Tengermellék és a fóváros, Budapest körzetére korlátozódtak.

Egy jó évtizeddel késóbb Somogyra vonatkoztatva PONGRÁcz (1914) a Fauna Regni Hungariae adatait idézi faunisztikai jellegú munkájában.

Ezt követôen több mint fél évszázadig nem találunk semmilyen publikált faunisztikai adatot a Somogy megyei recésszárnyú-alkatúakról. Sajnos ebból az idôszakból a hazai gyújitemények adataira sem támaszkodhatunk, mivel az egyetlen Neuroptera gyújtemény (Természettudományi Múzeum, Budapest) 
1956-ban teljesen elpusztult, így annak gazdag anyaga feldolgozás nélkül ismeretlen maradt.

A hatvanas évek elejétől azonban ismét egy-egy faj somogyi előfordulási helye bukkan fel STEINMANN (1963, 1964) és ÚjHELYI (1968) dolgozataiban.

A faunakutatás fehér foltjainak eltüntetésében igazi változást csupán a hazai tájkutatás elindulása hozott. 1975-tôl a Janus Pannonius Múzeum (Pécs) által szervezett Barcsi Borókás TK kutatása volt az elsố komplex jellegú fauna feltárást célzó vizsgálat Somogy megyében. Ennek keretében ÚJHELYI (1981, 1985) két rövid cikkben számolt be a tájvédelmi körzet recésszárnyú-alkatú faunájáról.

Így 1900-tól 1985-ig Somogy megyéról publikált lelőhelyi adatok (faj+lelóhely) száma összesen 57 volt, amely 39 fajhoz tartozott.

1985-tôl a Somogy Megyei Múzeum Természettudományi Osztályának létrejöttével és a szerzố egyik fó kutatási témájának köszönhetóen, Somogy megye Neuropteroidea faunája az eltelt 15 év alatt, az intenzív kutatómunka következtében, az ország többi területéhez viszonyítva jó kutatottságúnak mondható. Ma Somogy megye területéról 86 fajt ismerünk, amely a hazai fauna 65 \%-a. (Ábrahám 1992, 1995, 1998a, 1998b és ÁBRAHÁM - PAPP 1991, 1994).

Az elmúlt évek intenzív kutatásai során azonban néhány fajnak az állandó tenyészésú populációját nem sikerült ismét bizonyítani (pl.: Acanthaclisis occitanica, Myrmecaelurus punctulatus, Hemerobius simulans).

Hazánk legnagyobb hangyalesôjének, az Acanthaclisis occitanica-nak kaposvári lelöhelye (STEINMANN 1963), ismerve a faj ökológiai igényeit, habitatját, bizonytalannak túnik. Jelenleg a fajnak Kaposvár környékén biztosan nincs állandó populációja, hisz jellegzetes élóhelye, a nyilt homoki gyepek is hiányoznak.

A Myrmecaelurus punctulatus siófoki élōhelye (MOCSÁRY 1900, PONGRÁCZ 1914) a Balaton déli partvidékének homokturzásain lehetett, ezt erősíti számos hasonló ökológiai igényú faj felbukkanása erról a lelóhelyról. Sajnos a terepi munkálatok során, az elmúlt 15 évben nem találtunk alkalmas élóhelyet a faj számára. Feltételezhetốen a faj elterjedésének legnyugatabbi szegélypopulációja tû́nt el az urbanizált környezet terjeszkedésével.

A Hemerobius simulans faj (ÚJHELYI 1981) könnyen összetéveszthető a hozzá közel álló közönséges Hemerobius humulinus fajjal, ezért a Hemerobius simulans előfordulása szintén bizonytalannak tứnik.

Az elmúlt 15 évben azonban több nagyon ritka faj is elôkerült, melynek jelenlegi ismereteink szerint csupán egyetlen lelöhelye van a megyében (Phaeostigma major, Parainocellia braueri, Coniopteryx renate, Wesmaelius quadrifasciatus, Hemerobius perelagens, Sympherobius klapaleki, Nineta inpunctata, Chrysoperla mediterranea). Reméljük, hogy a következő évek kutatásai során még újabb fajok kerülnek elố és a most egyetlen populációjáról ismert fajok több lelöhelyról válnak majd ismertté.

A Chrysoperla carnea komplexet önálló fajokká az elmúlt néhány évben bontották szét. Somogy megyéból két fajt (Chrysoperla lucasina (Lacroix, 1912), Chrysoperla kolthoffi (Navas, 1927), sikerült azonosítani (Ábrahám 1998), bár ezek megkülönböztetése számos példány esetében azonban még bizonytalan.

A megyéből a hazai Neuropteroidea faunában elsóként kimutatott faj kettố volt Aleuropteryx juniperi (SZIRÁKI 1990) és a Myrmeleon bore (ÁBRAHÁM-PAPP, 1991), ezeknek hazai elterjedésének túlsúlya is Somogy megyére esik.

A megye területe a Neuroptera faunát tekintve eltérô mértékben kutatott. Jól feltárt területnek nevezhetố a Dráva mente, a Boronka-melléki Tájvédelmi Körzet, a Baláta-tó környéke és a Zselic területe. Különösen kevés adattal rendelkezünk Külső-Somogyból, melynek területét jórészt mezőgazdasági területek foglalják el, valószínưleg a Balaton déli partja még tartogat érdekességeket. 


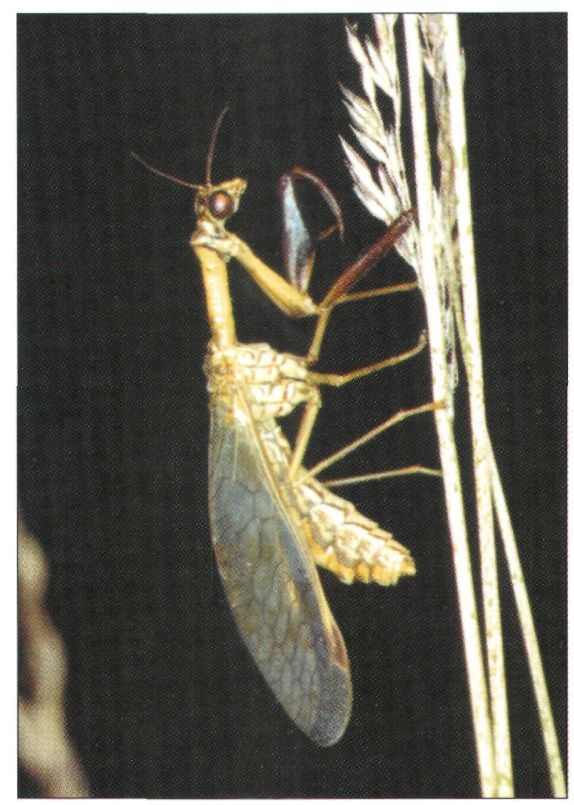

1. ábra: Fogólábú fátolyka - Mantispa styriaca Fotó: Ábrahám L.

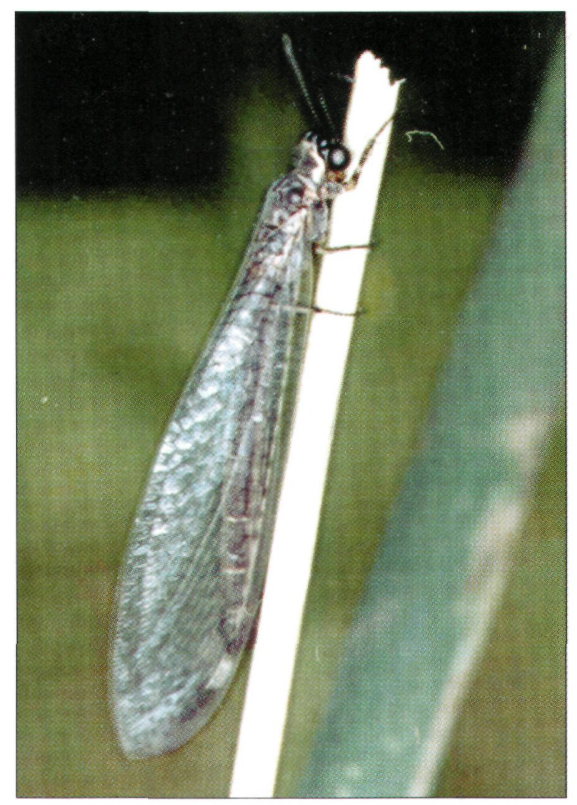

2. ábra: Hazánkban Somogy megyéból vált elôször ismertté a Myrmeleon bore Fotó: Ábrahám L. 


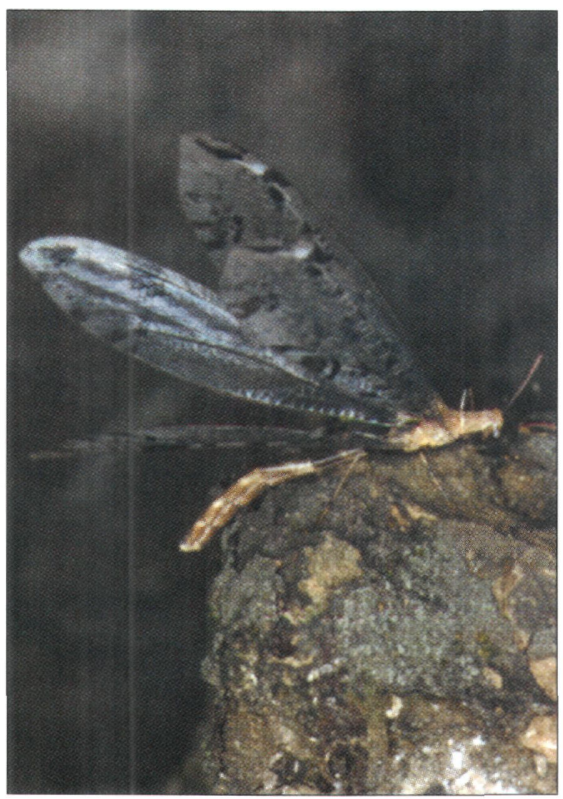

3. ábra: Párducfoltos hanygyaleső - Dendroleon pantherinus Fotó: Ábrahám L.

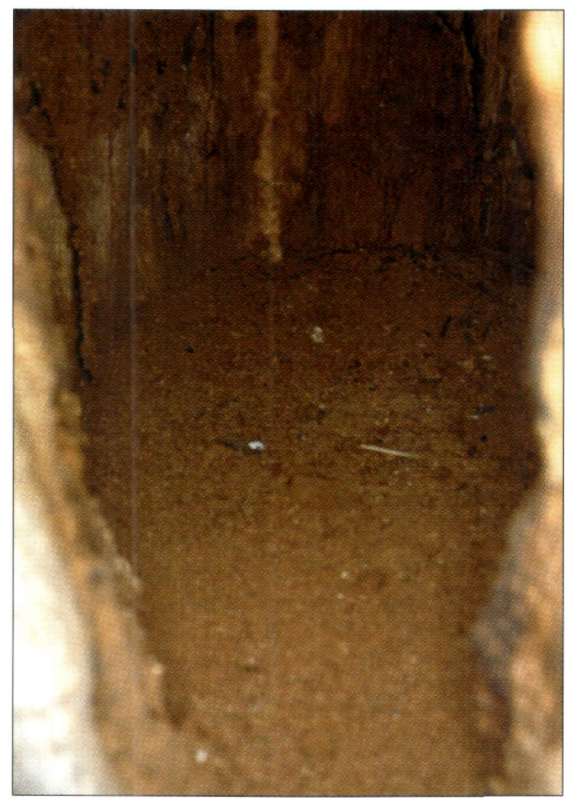

4. ábra: A Dendroleon pantherinus lárvája a többi hazai hangyaleső fajtól eltérôen nem laza talajon, hanem faodvakban él, ezért rendkívül ritka faj.

Fotó: Ábrahám L. 


\section{Somogyból ismert fajok jegyzéke}

\section{Megaloptera}

\section{Sialidae}

Sialis lutaria (Linnacus, 1758) - pol. extramed. és med. - Ábrahám 1992, 1995, 1998a

Sialis morio Klingstedt, 1932 - nem besorolható - Ábrahám 1992.

Sialis fuliginosa Pictet, 1836 pol. extramed. és med. - Ábrahám 1992,

\section{RAPHIDIOPTERA}

\section{Raphidiidae}

Phaeostigma notata (Fabricius, 1781) - exp. pol. extramed. európai - Ábrahám 1998a

Phaeostigma major (Burmeister, 1839) expansiv pontomediterrán - Ábrahám 1998a

Dichrostigma flawipes (Stein, 1863) - expansiv pon-tomediterrán - Coll: Somogy Megyei Múzeum

Subilla confinis (Stephens, 1836) - expansiv adriato-mediterrán - Ábrahám 1992, 1995,

Xanthostigma xanthostigma (Schummel, 1832) - szibériai - Újhelyi 1981, Ábrahám $1992,1995,1998$ a

\section{Inocelliidae}

Parainocellia braueri (Albarda, 1891) - Coll: Somogy Megyei Múzeum

\section{NEUROPTERA}

\section{Coniopterigydae}

Aleuropteryx juniperi Ohm, 1968 - holomediterrán - Sziráki 1990, Ábrahám 1995, 1998a

Helicoconis lutea (Wallangren, 1871) - policentrikus holarktikus - Ábrahám 1998a

Helicoconis pseudolutea Ohm, 1965 holomediterrán - Coll: Somogy Megyei Múzeum

Coniopteryx aspoecki Kis, 1967 - policentrikus szibériai mediterrán - Ábrahám 1995, $1998 \mathrm{a}$

Coniopteryx borealis Tjeder, 1930 - pol. extramed. és med. - Ábrahám 1995, 1998a

Coniopteryx pygmaea Enderlein, 1906 extrame-diterrán európai - Újhelyi 1981, Ábrahám 1992, 1995, 1998a

Coniopteryx hoelzeli Aspöck, 1964 - Ábrahám $1998 \mathrm{a}$
Coniopteryx tineiformis Curtis, 1834 - policentrikus holarktikus - Ábrahám 1995, 1998a

Coniopteryx haematica McLachlan, 1868 . expansiv holomediterrán - Ábrahám 1995, $1998 \mathrm{a}$

Coniopteryx renate Rausch et Aspöck, 1977 adriatomediterrán - Coll: Somogy Megyei Múzeum

Coniopteryx arcuata Kis, 1965 - holomediterrán - Ábrahám 1995 ,

Coniopteryx esbenpeterseni Tjeder, 1930 expansiv holomediterrán - Ábrahám 1995, 1998a

Coniopteryx lentiae Aspöck et Aspöck, 1964 holomediterrán - Ábrahám 1995, 1998a

Coniopteryx tjederi Kimmins, 1934 . holomediterrán - Ábrahám 1995, 1998a

Conwentzia pineticola Enderlein, 1905 . palaearktikus nem besorolható - Újhelyi 1981, Ábrahám 1995 ,

Conwentzia psociformis (Curtis, 1834) palaearktikus nem besorolható - Ábrahám 1995, 1998a

Semidalis aleyrodiformis (Stephens, 1836) nem besorolható holarktikus és orient. - Újhelyi 1981, Ábrahám 1992, 1995, 1998a

\section{Osmylidae}

Osmylus fulvicephalus (Scopoli, 1763) expansiv holomediterrán - Ábrahám 1998a, $1998 b$

\section{Sisyridae}

Sisyra fuscata (Fabricius, 1793) - DINODOL nem besorolható - Újhelyi 1985, Ábrahám 1992, 1995, 1998a, 1998b

Sisyra terminalis Curtis, 1854 - DINODOL Újhelyi 1985, Ábrahám 1995, 1998a, 1998b

\section{Mantispidae}

Mantispa styriaca (Poda, 1761) - expansiv holomediterrán - Ábrahám 1992, ÁbrahámPapp 1994, Ábrahám 1995, 1998a

\section{Hemerobiidae}

Hemerobius humulinus Linnaeus, 1758 - policentrikus holarktikus - Újhelyi 1981, Ábrahám 1992, 1995, 1998a

Hemerobius perelegans Stephens, 1836 - szibériai - Coll: Somogy Megyei Múzeum

Hemerobius simulans Walker, 1853 - policentrikus holarktikus - Újhelyi 1985 , 
Hemerobius stigma Stephens, 1836 - policentrikus holarktikus - Újhelyi 1981, Ảbrahám 1992, 1995,

Hemerobius pini Stephens, 1836 - szibériai Ábrahám 1992, 1995, 1998a

Hemerobius fenestratus Tjeder, 1932 - szibériai - Ábrahám 1995,

Hemerobius atrifrons McLachlan, 1868 - szibériai - Coll: Somogy Megyei Múzeum

Hemerobius nitidulus Fabricius, 1777 - policentrikus szibériai mediterrán - Újhelyi 1985, Ábrahám 1992, 1995,

Hemerobius handschini Tjeder, 1957. holomediterrán - Újhelyi 1985, Ábrahám 1992, 1995, 1998a

Hemerobius micans Olivier, 1792 - szibériai Ábrahám 1992, 1995, 1998a

Hemerobius lutescens Fabricius, 1793 - szibériai - Coll: Somogy Megyei Múzeum

Hemerobius marginatus Stephens, 1836 - szibériai - Ábrahám 1992, 1998a

Wesmaelius quadrifasciatus (Reuter, 1894). szibériai - Coll: Somogy Megyei Múzeum

Wesmaelius nerrosus (Fabricius, 1793) - szibériai - Ábrahám 1992, ヘ́brahám 1995,

Wesmaelius subnebulosus (Stephens, 1836) expansiv mediterrán - Úịhelyi 1968, 1985, Ábrahám 1992, 1998a

Sympherobius elegans (Stephens, 1836). expansiv holomediterrán - Ábrahám 1992, 1995, 1998a

Sympherobius pygnaeus (Rambur, 1842) expansiv holomediterrán - Újhelyi 1968, Ábrahám 1995, 1998a

Sympherobius fuscescens (Wallengren, 1863) szibériai - Újhelyi 1981, 1998a

Sympherobius klapaleki Zeleny, 1963 expansiv holomediterrán - Ábrahám 1995.

Psectra diptera (Burmeister, 1839) - policentrikus holarktikus - Újhelyi 1985, Ảbrahám 1992, 1995, 1998a

Drepanepteryx phalaenoides (Linnaeus, 1758) szibériai - Ábrahám 1992, Ábrahám 1995, 1998a

Micromus variegatus (Fabricius, 1793) - policentrikus szibériai mediterrán - Újhelyi 1968, Ábrahám 1992, Ábrahám 1995, 1998a

Micromus angulatus (Stephens, 1836) - policentrikus holarktikus - Újhelyi 1968, 1981, Ábrahám 1992, 1995, 1998a

\section{Chrysopidae}

Nothochrysa fulviceps (Stephens, 1836) extramediterrán európai - Ảbrahám 1992, $1995,1998 \mathrm{a}$
Hypochrysa elegans (Burmeister, 1839) - pol. extramed. és med. - Ábrahám 1995,

Nineta flava (Scopoli, 1763) - szibériai - Újhelyi 1981, Ábrahám 1992, 1995, 1998a

Nineta guadarramensis (Pictet, 1865) . holomediterrán - Ábrahám 1995,

Nineta inpunctata (Reuter, 1894) extramediterrán európai - Ábrahám 1995,

Chrysotropia ciliata (Wesmael, 1841) - szibériai - Újhelyi 1985, Ábrahám 1992, 1995, $1998 \mathrm{a}$

Chrysopa perla (Linnaeus, 1758) - szibériai Újhelyi 1981, Ábrahám 1992, 1995, 1998a

Chrysopa walkeri McLachlan, 1893 - expansiv pontomediterrán - Steinmann 1964, Ábrahám 1992, 1995,

Chrysopa dorsalis Burmeister, 1839 - expansiv pontomediterrán - Újhelyi 1981, Ábrahám 1992, 1995, 1998a

Chrysopa abbreviata Curtis, 1834 - szibériai -Ábrahám 1992, 1995,

Chrysopa formosa Brauer, 1850 - pol. szib. mongol és holomed. - Újhelyi 1981, Ábrahám 1992, 1995, 1998a

Chrysopa phyllochroma Wesmael, 1841 - szibériai - Újhelyi 1981, Ábrahám 1992, 1995, $1998 \mathrm{a}$

Chrysopa commata Kis et Újhelyi, 1965 expansiv pontomediterrán - Ábrahám 1992, 1995, 1998a

Chrysopa viridana Schneider, 1845 - expansiv holomediterrán - Újhelyi 1981, Ábrahám 1992, 1995,

Chrysopa nigricostata Brauer, 1850 - expansiv holomediterrán - Ábrahám 1992, 1995, I998a

Chrysopa pallens (Rambur, 1838) - palaearktikus nem besorolható - Újhelyi 1981, Ábrahám 1992, 1995, 1998a

Dichochrysa flavifrons (Brauer, 1850) expansiv holomediterrán - Ábrahám 1992, 1995, 1998a

Dichachrysa prasina (Burmeister, 1839) exp. pol. szib. mongol. és med. U Ujhelyi 198I, Ábrahám 1992, 1995, 1998a

Dichochrysa pentralis (Curtis, 1834) extramediterrán európai - Újhelyi 198I, Ábrahám 1992, 1995, 1998a

Peyerimhoffnia gracilis (Schneider, 1851) pol. extramed. és med.

Ábrahám 1992, 1995, 1998a

Chrysoperla carnea (Stephens, 1836) komplex kozmopolita - Újhelyi 1981, Ábrahám 1992, 1995, 1998a 
Chrysoperla mediterranea (Hölzel, 1972) atlanto-mediterrán - Coll: Somogy Megyei Múzeum

Cunctochrysa albolineata (Killington, 1935) policentrikus szibériai - Újhelyi 1981, Ábrahám 1992, 1995, 1998a

\section{Myrmeleontidae}

Acanthaclisis occitanica (Villers, 1789) expansiv holomediterrán - Steinmann 1963,

Nohoreus punctulatus (Steven, 1822) (=Myrmecaelurus zigan Aspöck et Aspöck et Hölzcl, 1980) - Mocsáry 1900, Pongrácz 1914,

Myrmeleon formicarius Linnaeus, 1767 - szibériai - Újhelyi 1985, Ábrahám 1992, 1995,

Myrmeleon inconspicuus Rambur, 1842 holomediterrán - Steinmann 1963, Ábrahám 1992, 1995, 1998a
Myrmeleon bore (Tjeder, 1941)- szibériai Ábrahám -Papp 1991, Ábrahám 1992, 1995, 1998a

Euroleon nostras (Geoffroy in Fourcroy, 1785) - pol. extramed. és med. - Steinmann 1963, Ábrahám 1992, 1998a

Dendroleon pantherinus (Fabricius, 1787) szibériai - Coll: Somogy Megyei Múzeum

Distoleon tetragrammicus (Fabricius, 1798) expansiv holomediterrán - Steinmann 1963, Újhelyi 1981, Ábrahám 1992, 1995, 1998 a

Creoleon plumbeus (Olivier, 1811) - expansiv pontomediterrán - Mocsáry 1900, Pongrácz 1914, Steinmann 1963, Újhelyi 1981, Ảbrahám 1992, 1995,

Megistopus flavicornis (Rossi, 1790) holomediterrán - Steinmann 1963, Újhelyi 1981, Ábrahám 1992, 1995, 1998a

\section{1. táblázat: Somogy faunájából ismert recésszárnyú-alkatúak (Neuropteroidea)} fajok, rendek és családonkénti megoszlása

\begin{tabular}{|l|c|}
\hline Rend, Család & Fajszám \\
\hline MEGALOPTERA & 3 \\
\hline Sialidae & 3 \\
\hline RAPHIOIOPTERA & 6 \\
\hline Raphidiidae & 5 \\
\hline Inocelliidae & 1 \\
\hline NEUROPTERA & 77 \\
\hline Coniopterigydae & 17 \\
\hline Sisyridae & 2 \\
\hline Osmylidae & 1 \\
\hline Mantispidae & 1 \\
\hline Hemerobiidae & 23 \\
\hline Chrysopidae & 23 \\
\hline Myrmeleontidae & 10 \\
\hline
\end{tabular}

\section{Irodalom}

ÁBRAHÁM, L. 1992: A Boronka-melléki Tájvédelmi Körzet nagyszárnyú, tevenyakú és recésszárnyú faunájának természetvédelmi értékelése (Megaloptera, Raphidioptera, Neuroptera) - Dunántúli Dolgozatok Természetudományi Sorozat 7: 107-125.

ÁBRAHÁM, L. 1995: A tervezett Duna-Dráva Nemzeti Park recésszárnyú-alkatú (Megaloptera, Raphidioptera, Neuroptera) faunájának természetvédelmi vizsgálata, I. - Dunántúli Dolgozatok Természetudományi Sorozat 8. 53-70.

ÁbrAHÁM, L. 1998a: Natural protection studies on the neuropteroids (Megaloptera, Raphidioptera, Neuroptera) fauna of the Duna - Dráva National Park, II. - Dunántúli Dolgozatok Természetudományi Sorozat 9: 269-289.

ÁBRAHÁM, L. 1998b: A study on the Hungarian freshwater osmylid and sponge-flies fauna (Neuroptera: Osmylidae, Sisyridae) - Somogyi Múzeumok Közleményei 14: 263-273.

ÁBRAHÁM, L. - PAPP Z. 1991: Myrmeleon bore (Tjeder, 1941) in Hungary (Planipennia, Myrmeleontidae) - Neuroptera International 6 (3): 137-139. 
ÁBKHHAM, L. - PAPl, Z. 1994: Mantispids species in the Hungarian fauna with some taxonomical remarks (Neuroptera: Mantispidae) - Fol. Hist. Nat. Mus. Matraensis 19: 69-75.

MOCSÁRY, S. 1900: (Neuroptera) Fauna Regni Hungariae - A Magyar Birodalom Állatvilága - Bp., pp. 33-44.

PONGRÁCZ, S. 1914: Magyarország Neuropteroidái - Rovartani Lapok 21: 109-155.

SteinmanN, H. 1963: Magyarország hangyalesői (Neuroptera) - Rovartani Közl. 16: 211-226.

Steinmann, H. 1964: The Chrysopa species of Hungary - Ann. Hist. Nat. Hung. 56: 257-266.

SzIrÁKI, Gy. 1990: Az Aleuropteryx juniperi Ohm, elsó hazai észlelése (Planipennia, Coniopterygidae) - Fol. ent. hung. 51:167-168.

Ú JHELYI, S. 1981: A Barcsi Borókás recésszárnyú és tegzes faunájának alapvetése - Dunántúli Dolgozatok Természeudománvi Sorozat 2: 59-63.

ÚlHELYI, S. 1985: Kiegészítés a Barcsi Borókás Recészárnyúihoz (Neuroptera) - Dunántúli Dolgozatok Természctudományi Sorozat 4: 234.

\title{
Checklist of the neuropteroid fauna of Somogy county (Megaloptera, Raphidioptera, Neuroptera)
}

\section{LEVENTE ÁBRAHর́M}

Somogy county is located in the Southwest Hungary. From this area, 86 species of neuropteroid have become known, comprising 3 Megaloptera, 6 Raphidioptera and 77 Neuroptera.

The first faunistical data from this area dates back to the beginning of the last century. With the exception of the past 15 years, intensive fieldwork was not carried out in this region.

The rarest species are: Phaeostigma major, Parainocellia brueri, Coniopteryx renate, Wesmaelius quadrifastiatus, Hemerobius perelagans, Sympherobius klapaleki, Nineta inpunctata, Chrysoperla mediterranea.

Two species, Aleuropteryx juniperi and Myrmeleon bore, found in Somogy county, were new for the Hungarian lacewing fauna.

In spite of the intensive fieldwork during the past 15 years, three species still could not be proved to exist: Acanthaclisis occitanica, Hemerobius simulans, Myrmecaelurus punctulatus.

Distribution data to the lacewing fauna of this area were found in 13 publications. The representative neuropteroid collection of the region is owned by the Natural History Department of Somogy County Museum.

\author{
Author's address: \\ Dr. Levente ÁBrAHÁM \\ Natural History Department \\ Somogy County Museum \\ H-7400 Kaposvár \\ Fó utca 10. P.o. Box 70. \\ HUNGARY
}

